\title{
Ocular Vascular Disorder
}

National Cancer Institute

\section{Source}

National Cancer Institute. Ocular Vascular Disorder. NCI Thesaurus. Code C35664.

A disorder that is caused by pathologic changes in the ocular vasculature. 